\title{
IV SEMINÁRIO INTERNACIONAL CULTURA MATERIAL E PATRIMÔNIO DA CIÊNCIA E TECNOLOGIA (IVSPCT)
}

MARCUS GRANATO, MUSEU DE ASTRONOMIA E CIÊNCIAS AFINS, RIO DE JANEIRO, RIO DE JANEIRO, BRASIL.

Coordenador de Museologia do Museu de Astronomia e Ciências Afins do Ministério de Ciências e Tecnologia, E-mail: marcus@mast.br

DOI

http://dx.doi.org/10.11606/issn.1980-4466.v0i23p279-283 
O Museu de Astronomia e Ciências Afins (MAST), por intermédio de seu grupo de pesquisa "Museologia e Preservação de Acervos Culturais", organizou o quarto Seminário Internacional Cultura Material e Patrimônio da Ciência e Tecnologia (Ivspct) para discutir aspectos relacionados ao patrimônio cultural da ciência e tecnologia (C\&T), tendo como referencial o arcabouço da cultura material. $\mathrm{O}$ evento contou com especialistas de várias instituições que se manifestaram sobre temas específicos, por meio de mesas redondas e conferência, constituindo-se também em espaço para apresentação de trabalhos que foram avaliados e selecionados pelo Comitê Científico do evento. ${ }^{1}$

O evento, realizado entre 5 e 8 de dezembro de 2016, foi aberto a todos aqueles interessados na preservação, documentação e uso do patrimônio cultural de C\&T, entendido em amplo espectro como o conjunto tangível e intangível relacionado à $C \& T$, a que se atribuem valores que justificam sua preservação para as futuras gerações. Inclui o conhecimento científico e tecnológico produzido pelo homem, além dos saberes, das práticas de ensino e pesquisa, e de todos aqueles artefatos e espécimes que são testemunhos dos processos científicos, de desenvolvimento tec-

1. Os Anais do IV Seminário Internacional Cultura Material e Patrimônio da Ciência e Tecnologia estão disponíveis em: $<$ http://site.mast.br/hotsite_anais_ivspct_2/index.html $>$. 
nológico e de ensino, considerando documentos em suporte papel (arquivísticos e bibliográficos), instrumentos científicos, máquinas, montagens, coleções científicas de natureza diversa como arqueológicas, etnográficas, biológicas, além de construções arquitetônicas produzidas com a funcionalidade de atender às necessidades desses processos e desenvolvimentos (laboratórios, observatórios, paisagens e jardins).

Entre os palestrantes convidados que participaram do primeiro dia do evento, podem ser citadas Marta Lourenço (Museu Nacional de História Natural e da Ciência, Universidade de Lisboa), que proferiu a conferência de abertura sobre os "Desafios e problemas colocados pelo patrimônio e coleções científicas à pesquisa contemporânea"; Emanuela Sousa Ribeiro (Universidade Federal de Pernambuco) e Mônica Junqueira de Camargo (Centro de Preservação Cultural da USP), que fizeram parte da mesa de discussão sobre "Preservação do patrimônio de C\&T no Brasil: desafios e perspectivas", em que se procurou estimular o debate com os participantes, de forma a identificar aspectos positivos e negativos nos desenvolvimentos dos últimos dez anos; propor estratégias para a melhor preservação em amplo espectro; e estimular a participação na elaboração de uma carta patrimonial específica sobre esse tipo de patrimônio.

Nos três dias seguintes, o programa foi estruturado com uma mesaredonda pela manhã e sessões de apresentações de trabalhos na parte da tarde. Os temas e participantes das mesas foram os seguintes:

"O Patrimônio de C\&T e as Universidades": Verona Campos Segantini (UFMG), Nadja Paraense dos Santos (UFRJ), Marta Lourenço (Museus da Universidade de Lisboa/UMAC-ICOM).

"O Patrimônio de C\&T e as Escolas de Ensino Médio: Katya Mitsuko Zuquim Braghini (PUC-SP), Maria Cristina de Senzi Zancul (UNESP), Vânia Maria Siqueira Alves (UNIMONTES).

"Museus e a Preservação do Patrimônio de C\&T": Marcio Rangel (MAST), Aline Rocha de Souza F. de Castro (Museu da Geodiversidade/ UFRJ) e Nelson Sanjad (Museu Goeldi).

As sessões de apresentação de trabalhos possibilitaram que 48 contribuições fossem discutidas, sendo 11 na forma de pôsteres, congregando participantes de vários estados e instituições brasileiras. No total, inscreveram-se e participaram do evento mais de 70 profissionais e estudantes de pós-graduação. 
A iniciativa de realizar eventos sobre o patrimônio de C\&T tem por motivação principal o alto risco de desaparecimento da materialidade relacionada a esse tipo de patrimônio. A grande maioria dos artefatos e mesmo dos poucos espaços que se dedicam a sua preservação no país são invisíveis para a sociedade e o grande público, mas também para os próprios cientistas e professores, que são atores importantes no processo de geração e utilização desses objetos em seu circuito de uso original.

As pesquisas e atividades desenvolvidas e que foram relatadas e discutidas no evento se dedicam a estudar os bens produzidos e/ou utilizados nas atividades de ensino, pesquisa científica e de desenvolvimento tecnológico. Ou seja, aqueles bens que participaram do cotidiano dos laboratórios de pesquisa, das universidades e escolas do país e contribuíram para o desenvolvimento da ciência e tecnologia no Brasil.

Como resultados principais do evento, além da ampla possibilidade de intercâmbio de ideias e experiências entre os participantes, identificou-se:

- a oportunidade de elaborar a carta patrimonial já mencionada, o que deverá acontecer até maio de 2017;

- o estímulo a iniciativas de solicitação de tombamento de bens móveis e imóveis do patrimônio de C\&T, tanto em nível federal como estadual. Nesse caso, foram identificadas pelo menos duas boas oportunidades nas coleções sob a guarda do Museu Dinâmico de Ciência e Tecnologia da Universidade Federal de Juiz de Fora, e no avião Muniz M-7, o primeiro modelo fabricado em série no Brasil pela Fábrica Brasileira de Aviões, sob a guarda do Museu da Aeronáutica;

- organizar cursos de curta duração e oficinas sobre temas relacionados à preservação desse tipo de patrimônio, além de materiais didáticos destacando as boas práticas, especialmente de inventário;

- traduzir e divulgar textos de destaque sobre o assunto, publicados em outros idiomas, para facilitar o intercâmbio de informações no país;

- elaborar um projeto de médio a longo prazo, articulando instituições interessadas no tema para captar recursos em agências de financiamento e permitir o avanço do conhecimento e das 
práticas de preservação do patrimônio de C\&T;

- estabelecer contatos e fazer articulações políticas com órgãos e instituições que possam colaborar para a preservação do patrimônio de C\&T (exemplo: Iphan, Academia Brasileira de Ciências, SBPC, Fóruns de Pró-Reitores de universidades, Ministério Público, Ibram, MCTIC, MINC, MEC etc.).

A avaliação realizada ao final do evento, durante seu encerramento, foi positiva e espera-se que, em 2018, seja possível realizar o V SPCT e que pelo menos algumas dessas iniciativas tenham se realizado. 